\title{
Early Maladaptive Schemas in Obsessive-Compulsive Disorder and Anxiety Disorders
}

\author{
Afsaneh Yoosefi ${ }^{1,2}$, Sepideh RajeziEsfahani ${ }^{1}$, Abbas Pourshahbaz ${ }^{2}$, Behrooz Dolatshahee ${ }^{2}$, Abbasali Assadi ${ }^{2}$, \\ Fahime Maleki $^{2} \&$ Sara Momeni $^{1}$ \\ ${ }^{1}$ Behavioral Sciences Research Center of Shahid Beheshti University of Medical Sciences, Tehran, Iran \\ ${ }^{2}$ Clinical Psychology Department, University of Social Welfare and Rehabilitation sciences, Tehran, Iran \\ Correspondence: Abbas Pourshahbaz, Clinical Psychology Department, University of Social Welfare and \\ Rehabilitation Sciences, Tehran, Iran. Tel: 98-21-2218-0045. E-mail: apourshahbaz@yahoo.com
}

Received: September 23, 2015 Accepted: October 28, 2015 Online Published: February 24, 2016

doi:10.5539/gjhs.v8n10p167 URL: http://dx.doi.org/10.5539/gjhs.v8n10p167

\begin{abstract}
Background: Purpose of this study is comparing early maladaptive schemas which are active in patients suffering from obsessive-compulsive disorder and anxiety disorders together, considering recent DSM- 5 changes through which OCD has been placed in a separate and new diagnostic level.
\end{abstract}

Methodology: This research is a causal-comparative study. 151 persons were categorized in three groups of people suffering from OCD (50), suffering from anxiety disorders (50), and control group (51). Early diagnosis of disorders in two clinical groups were verified based on structured clinical interview for DSM (SCID-I) and Yale-Brown obsessive-compulsive scale (Y-BOCS). General health questionnaire (GHQ-28), the short versions of the Young schemas questionnaire (YSQ), and Padua inventory-Washington State University Revision (PI-WSUR) were also implemented.

Findings: Findings revealed that mean scores of all schemas of those suffering from anxiety disorders, except for Self-Sacrifice, Unrelenting-Standards/Hypercriticalness, Entitlement/Grandiosity schemas, and mean scores of all early maladaptive schemas of those suffering from obsessive compulsive disorder are significantly higher than those of control group. OCD group had significantly higher scores in Emotional Deprivation, Mistrust/Abuse, and Defectiveness/Shame schemas than anxiety disorders group. Defectiveness/Shame and Vulnerability to Harm or Illness schemas can explain 38 percent of variance of obsessive compulsive symptoms.

Conclusion: The dominant and specific early maladaptive schemas of OCD are Defectiveness/Shame, Mistrust/Abuse, and Emotional Deprivation Schemas. This study besides supporting the theory of early maladaptive schemas, suggests that interventions based on specific schemas can be useful methods in treatment of OCD and anxiety disorders.

Keywords: early maladaptive schemas, anxiety disorders, obsessive-compulsive disorder

\section{Introduction}

Early maladaptive schemas (EMSs) are among the most important components of cognitive theory of psychological disorders (Young, Klosko, \& Weishaar, 2003). These schemas represent core beliefs about self and others and mislead external information process into a dysfunctional way (Pinto-Gouveia, Castilho, Galhardo, \& Cunha, 2006). Broadly speaking, in the context of psychology and psychotherapy, schema is considered as a general structuring principle which is essential in one's perception of life experiences (Young, 1994; Young et al., 2003) and is known as the deepest cognitive levels (Young et al., 2003). In comparison with other cognitive vulnerabilities, EMSs are more unconditional and automatic and are able to produce high levels of negative affections (Harris \& Curtin, 2002). Young created the schema theory for the patients with severe and chronic psychological problems who could not benefit the traditional cognitive treatments and required a more comprehensive treatment approach due to their problems in recognizing and changing beliefs and emotions (Hawke \& Provencher, 2011).

According to this theory, activation of maladaptive schemas and development of high levels of negative affections will directly or indirectly cause psychological disorders such as interpersonal maladaptation, depression, anxiety, job incompetency, and drug addiction (Nordahl, Holthe, \& Haugum, 2005). Many researches have been conducted 
in this regard in different fields such as antisocial personality, avoidant personality, depressed personality, paranoid personality, dependent personality, borderline personality, and obsessive compulsive personality disorders which reveal a high correlation between early maladaptive schemas and these disorders (Ball \& Cecero, 2001; Carr \& Francis, 2010; Jovev \& Jackson, 2004; Nordahl et al., 2005; Petrocelli, Glaser, Calhoun, \& Campbell, 2001; Reeves \& Taylor, 2007; Sines, Waller, Meyer, \& Wigley, 2008; Specht, Chapman, \& Cellucci, 2009). The findings of some researches on eating disorder also represented that the Emotional Deprivation, Social Isolation/Alienation, Defectiveness/Shame, Failure, Dependence/Incompetence, and Subjugation schemas are remarkably high in those patients (Anderson, Rieger, \& Caterson, 2006; Leung, Waller, \& Thomas, 1999; Moloodi, Dezhkam, Mootabi, \& Omidvar, 2010; Riso, du Toit, Stein, \& Young, 2007; Van Vlierberghe \& Braet, 2007; Voderholzer et al., 2014; Waller, Meyer, \& Ohanian, 2001), on the other hand active schemas in people suffering from drug abuse disorder are reported to be Subjugation, Vulnerability to Harm or Illness, and Emotional Inhibition (Ball \& Cecero, 2001; Brotchie, Meyer, Copello, Kidney, \& Waller, 2004). Findings of researches confirm a relation between EMSs and depression disorder (Abela, Auerbach, Sarin, \& Lakdawalla, 2009; Lumley \& Harkness, 2007; Riso \& Newman, 2003). Moreover, patients suffering from anxiety disorders obtained higher scores in a number of EMSs (Brewin, Andrews, \& Valentine, 2000; Cockram, Drummond, \& Lee, 2010; Delattre et al., 2004; Dutra, Callahan, Forman, Mendelsohn, \& Herman, 2008; Hedley, Hoffart, \& Sexton, 2001; Hinrichsen, Waller, \& Emanuelli, 2004; Pinto-Gouveia et al., 2006). As mentioned above, findings show that EMSs varies in different disorders. According to the relation between some special schemas and advent of psychological symptoms, and also due to 6.8 percent prevalence of anxiety disorders as the most widespread psychological disorders (Mohammadi et al., 2005; Mohammadi et al., 2004), studying these cognitive structures in people suffering from anxiety disorders would greatly help clarifying the role of EMSs in development of these disorders and consequently in treatment of patients.

There is not any comprehensive information about the structure of psychological disorders schemas at hand (Beck, Freeman, \& Davis, 2004). However some researches can be mentioned in this filed such as Delattre et al. (2004) about EMSs of anxiety disorders (Delattre et al., 2004); Hedley et al. (2001) and Kwak \& Lee (2015) about schemas of panic disorder (Hedley et al., 2001; Kwak \& Lee, 2015); Hinrichsen (2004) (Hinrichsen et al., 2004) and Pinto Gouveya et al. (2006) (Pinto-Gouveia et al., 2006) about EMSs of social anxiety disorder; Edworthy et al (2008) (Edworthy, Chasey, \& Williams, 2008), Dutra et al. (2008) (Dutra et al., 2008), and Cockram et al. (2010) (Cockram et al., 2010) about EMSs of post-traumatic stress disorder; Atalay et al. (2008) (Atalay, Atalay, Karahan, \& Çaliskan, 2008), Noie et al. (2009) (Noie, Farid, Fata, \& Ashoori, 2010), Lochner et al. (2005) (Lochner et al., 2005), Kim et al. (2014) (Kim, Lee, \& Lee, 2014) about EMSs of OCD disorder. Their most important limitations are as following: first, none of them is based on DSM-5 in which OCD is studied in a separate category from anxiety disorders; second, they do not compare OCD and anxiety disorders groups alongside a control group. Besides, Iranian study may provide the researchers with different findings from those of other cultures about active schemas of OCD and anxiety disorders.

With respect to the fact that EMSs can be central in chronic disorders of axis I, and considering the separate categorization of OCD from anxiety disorders in DSM-5; this study, through specification of these cognitive structures in people suffering from anxiety disorders and OCD, seeks to clarify the EMSs role in development of these disorders and compare their early maladaptive schemas together, moreover, specifically find out that which early maladaptive schemas predict the obsessive-compulsive symptoms.

\section{Methodology}

This study is a cross sectional-comparative research.

Statistical society of this research includes people suffering from OCD and anxiety disorders (phobia, general anxiety, social anxiety, panic, acute stress, post-traumatic stress disorder) who referred to psychology and psychiatry clinics in Tehran (2014). Through targeted sampling and based on previous studies (Manesh, Baf, Abadi, \& Mahram, 2010; Noie et al., 2010; Pinto-Gouveia et al., 2006), two groups of fifty patients were selected. There were two inclusion criteria in the present study: First, verifying the diagnosis of anxiety disorder and OCD as the main diagnosis (lacking comorbidity with other disorders of axis I and II) through structured clinical interview (SCID-I); and second, participants' gaining score less than less than 9 for anxiety disorders and higher than 9 for OCD patients (Iranian cut off point) from Yale-Brown severity scale. Control groups includes 51 volunteers whose mental health had been verified based on gaining a score less than 23 of general health questionnaire and a score less than 9 of Y-BOCS questionnaire. After choosing three groups, the Young schemas questionnaire (the short form) and Padua inventory (PI-WSUR) were performed. Variables of Gender ( $\mathrm{x} 2=0.35$, $\mathrm{P}<0.05)$, age $(\mathrm{F}=1.33, \mathrm{P}<0.05)$, marital status $(\mathrm{x} 2=3.80, \mathrm{P}<0.05)$, and education $(\mathrm{x} 2=2.93, \mathrm{P}<0.05)$ were not significantly different in three groups of $\mathrm{OCD}$, anxiety disorders and control. It can be concluded that the effects of 
these variables are controlled.

In order to compare early maladaptive schemas of the three groups, one-way ANOVA was used, and to predict the symptoms of Obsessive Compulsive by early maladaptive schemas, stepwise regression was used.

\subsection{Research Tools}

The bellow tools have been used in this research:

1- Structured clinical interview for DSM: It was prepared by First, Spitzer, Gibbon and Williams in 1996. It evaluates the main psychiatric disorders (axil I and II of DSM-IV) based on the fourth edition of diagnostic and statistical manual of mental disorders (First, Spitzer, Gibbon, \& Williams, 1997). The version used in this study was SCID-I translated and adjusted with the original text by Mohammadkhani et al. (2006) (Mohammadkhani, Jahanitabesh , \& Tamanaii far, 2006).

2- Yale-Brown obsessive compulsive severity scale: In 1989, Goodman et al. compiled Y-BOCS scale which is a 10-item clinical index and evaluates symptoms of obsessive thoughts apart from compulsions, each of its items is graded 0 to 4 regarding symptom severity, frequency, duration and patient's resistance to perform the rituals (Goodman et al., 1989). The internal consistency coefficient is reported 0.89 through Cronbach's alpha coefficient (Taylor SIRPS, 1998). Cut-off point of 9 was reported for discrimination between patients and healthy people in Iran (Rajezi Esfahani S, 2012).

3- General health questionnaire: This is a 28-question form prepared by Goldberg and Hillier in 1979 with eligible validity and reliability in order to discriminate between patients and healthy people (Goldberg \& Hillier, 1979). It contains four subscales of somatic symptoms, anxiety and insomnia, social dysfunction and depression. Nazifi et al. (2013) have reported its internal consistency as 0.92 based on Cronbach alpha coefficient (Nazifi et al., 2014).

4- Short form of Young schemas questionnaire: This self-report questionnaire prepared by Young and Brown in 1999 (Young, 1999) measures EMSs by 75 questions and in 15 subscales. Each five questions in this questionnaire measure one schema. Any schema that gains the highest score will be regarded as the patient's schema. The first comprehensive research about psychometric characteristics of these schemas, is done by Schmidt, Joiner, Young and Telch in 1995 (Schmidt, Joiner Jr, Young, \& Telch, 1995) and demonstrates the test's acceptable validity and reliability (Calvete, Estévez, López de Arroyabe, \& Ruiz, 2005; Hadibahrami \& Bahramizadeh, 2011). Based on Cronbach alpha coefficient, Ahi (2006) has reported internal consistency in female group as 0.97 and in male group as 0.98 (Ahi, 2006).

5- Padua inventory- Washington State University Revision (PI-WSUR): This questionnaire was codified in Washington State University by Burns et al. in 1995. It contains 39 items and aims at evaluation and measurement of obsessive compulsive disorder (Burns, Formea, Keortge, \& Sternberger, 1995). Each item is divided into 5 scales based on the severity of discomfort resulted by thoughts or behaviors (from "not at all" $=0$ to "a lot" $=4$ ). Five factors related to OCD are contamination obsession and washing compulsions (10 items), dressing/grooming compulsion (3 items), checking compulsion (10 items), obsessional thoughts about harm to self/others (7 items), and obsessional impulses to harm self/others (9 items). Shams et al. reported the Cronbach's alpha coefficient as 0.92 and stability resulted from retest method as 0.77 (Shams, Kaviani, Esmaili, Ebrahimkhani, \& Amin, 2010).

\section{Conclusion}

In order to study the normal distribution of the gained data, the Kolmogorov-Smirnov test was used which showed that distribution of data was normal in EMSs (Figure 1). 


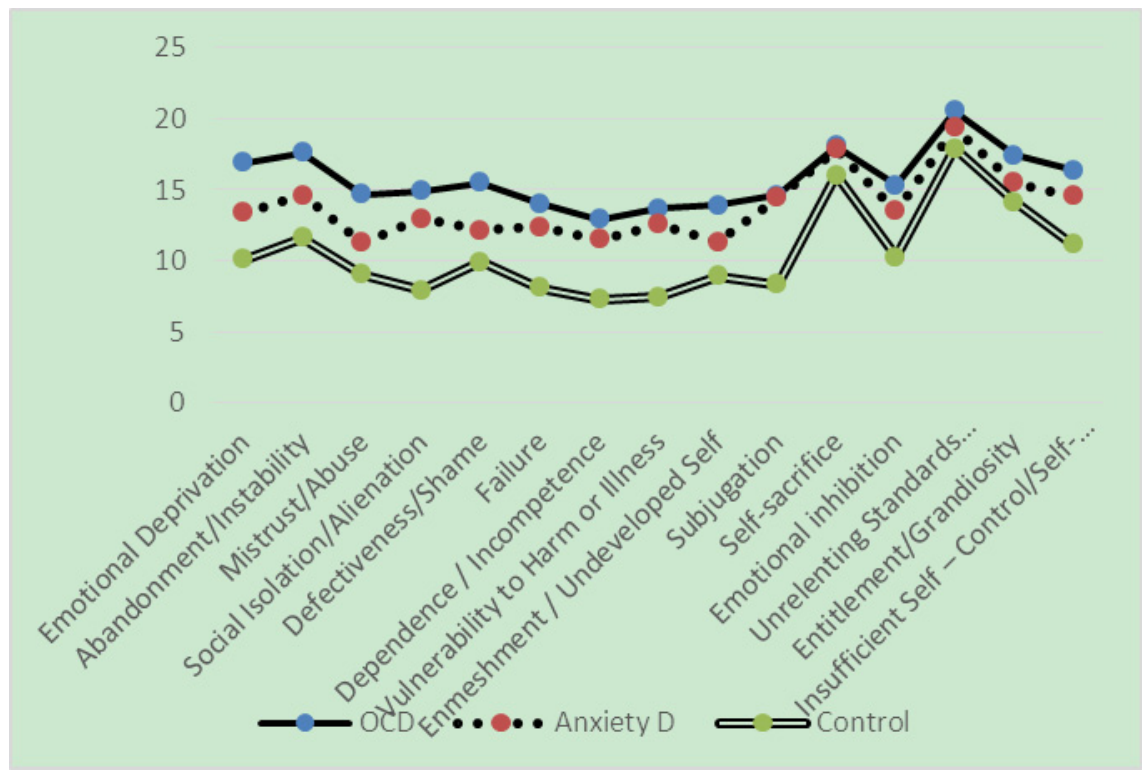

Figure 1. Distribution of mean early maladaptive schemas in three groups

The comparison of three groups through one-way ANOVA with the p value of 0.003 according to benferroni correction (0.05 divided to 15) showed that with the exception of three schemas of Self-sacrifice, Unrelenting Standards/Hypercriticalness, and Entitlement/Grandiosity, there are significant differences among three groups in the all early maladaptive schemas (Table 1). Tamhane's T2 post hoc test illustrates that patients suffering from anxiety disorders except in the three above-mentioned schemas, and OCD patients in all of the early maladaptive schemas gained significantly higher scores than control groups, Moreover; OCD group members gained higher scores than patients in anxiety disorders group in Emotional Deprivation, Mistrust/Abuse, and Defectiveness/Shame schemas (Table 1).

Table 1. Mean, standard deviation and variance analysis of three groups of OCD, anxiety disorders, and control in EMSs.

\begin{tabular}{lllllll}
\hline & OCD & AD & C & & & \\
\hline Scale & $\mathrm{M}(\mathrm{SD})$ & $\mathrm{M}(\mathrm{SD})$ & $\mathrm{M}(\mathrm{SD})$ & $\mathrm{f}$ & $\mathrm{P}$ value & Post hoc \\
\hline Emotional Deprivation & $16.88(7.43)$ & $13.36(5.57)$ & $10.09(5.10)$ & 15.27 & 0.000 & $\mathrm{OCD}>\mathrm{AD}>\mathrm{C}$ \\
Abandonment/Instability & $17.60(7.57)$ & $14.63(5.83)$ & $11.60(5.30)$ & 11.23 & 0.000 & $\mathrm{OCD}, \mathrm{AD}>\mathrm{C}$ \\
Mistrust/Abuse & $14.70(7.42)$ & $11.28(5.53)$ & $9.05(3.35)$ & 12.55 & 0.000 & $\mathrm{OCD}>\mathrm{AD}>\mathrm{C}$ \\
Social Isolation/Alienation & $14.92(7.41)$ & $12.95(6.07)$ & $7.90(3.03)$ & 18.93 & 0.000 & $\mathrm{OCD}, \mathrm{AD}>\mathrm{C}$ \\
Defectiveness/Shame & $15.50(6.12)$ & $12.12(2.72)$ & $9.92(2.51)$ & 21.94 & 0.000 & $\mathrm{OCD}>\mathrm{AD}>\mathrm{C}$ \\
Failure & $14.02(6.96)$ & $12.38(6.51)$ & $8.07(4.05)$ & 13.45 & 0.000 & $\mathrm{OCD}, \mathrm{AD}>\mathrm{C}$ \\
Dependence/Incompetence & $12.92(7.05)$ & $11.52(4.86)$ & $7.29(3.18)$ & 15.17 & 0.000 & $\mathrm{OCD}, \mathrm{AD}>\mathrm{C}$ \\
Vulnerability to Harm or Illness & $13.70(7.91)$ & $12.58(6.90)$ & $7.47(4.14)$ & 13.03 & 0.000 & $\mathrm{OCD}, \mathrm{AD}>\mathrm{C}$ \\
Enmeshment/Undeveloped Self & $13.90(6.71)$ & $11.33(5.67)$ & $8.90(4.82)$ & 9.39 & 0.000 & $\mathrm{OCD}, \mathrm{AD}>\mathrm{C}$ \\
Subjugation & $14.64(6.77)$ & $14.44(6.75)$ & $8.33(3.49)$ & 18.65 & 0.000 & $\mathrm{OCD}, \mathrm{AD}>\mathrm{C}$ \\
Self-sacrifice & $18.08(6.11)$ & $17.83(5.90)$ & $16.00(5.91)$ & 1.76 & 0.175 & $\mathrm{OCD}>\mathrm{C}$ \\
Emotional inhibition & $15.32(6.94)$ & $13.50(6.39)$ & $10.28(4.74)$ & 7.02 & 0.000 & $\mathrm{OCD}, \mathrm{AD}>\mathrm{C}$ \\
Unrelenting Standards & $20.56(6.25)$ & $19.38(5.56)$ & $17.92(6.82)$ & 2.76 & 0.067 & $\mathrm{OCD}>\mathrm{C}$ \\
/Hypercriticalness & $17.46(5.88)$ & $15.52(5.07)$ & $14.13(5.31)$ & 4.68 & 0.011 & $\mathrm{OCD}>\mathrm{C}$ \\
Entitlement/Grandiosity & $16.38(5.83)$ & $14.58(5.84)$ & $11.15(3.87)$ & 13.12 & 0.000 & $\mathrm{OCD}, \mathrm{AD}>\mathrm{C}$ \\
Insufficient Self-Control/Self-discipline & & & & & &
\end{tabular}

Note. $\mathrm{AD}=$ Anxiety disorder, $\mathrm{C}=$ control 
In order to predict the obsessive compulsive symptoms, Pearson correlation coefficient was calculated among EMSs and general score of obsessive compulsive symptoms and its subscales (Table 2) and then the stepwise regression was used (Table 3).

Table 2. Pearson correlation matrix among 15 early maladaptive schemas and Padua's general score and its 5 subscales

\begin{tabular}{|c|c|c|c|c|c|c|}
\hline Scale & Padua & COWC & DRGRC & CHCK & OTAHSO & OITHSO \\
\hline Emotional Deprivation & $0.35 * *$ & $0.25 * *$ & 0.15 & $0.30 * *$ & $0.38^{* *}$ & $0.31^{* *}$ \\
\hline Abandonment/Instability & $0.40 * *$ & $0.30 * *$ & $0.25 * *$ & $0.27 * *$ & $0.44 * *$ & $0.41 * *$ \\
\hline Mistrust/Abuse & $0.47 * *$ & $0.36^{* *}$ & $0.31 * *$ & $0.34 * *$ & $0.53 * *$ & $0.38 * *$ \\
\hline Social Isolation/Alienation & $0.53 * *$ & $0.49 * *$ & $0.31 * *$ & $0.44 * *$ & $0.50 * *$ & $0.40 * *$ \\
\hline Defectiveness/Shame & $0.54 * *$ & $0.44 * *$ & $0.33 * *$ & $0.38 * *$ & $0.55 * *$ & $0.49 * *$ \\
\hline Failure & $0.41 * *$ & $0.25 * *$ & $0.17^{*}$ & $0.37 * *$ & $0.49 * *$ & $0.39 * *$ \\
\hline Dependence/Incompetence & $0.42 * *$ & $0.35^{* *}$ & $0.23 * *$ & $0.28 * *$ & $0.51 * *$ & $0.31 * *$ \\
\hline Vulnerability to Harm or Illness & $0.53 * *$ & $0.37 * *$ & $0.21 *$ & $0.43 * *$ & $0.67 * *$ & $0.44 * *$ \\
\hline Enmeshment/Undeveloped Self & $0.45^{* *}$ & $0.38 * *$ & $0.20 *$ & $0.34 * *$ & $0.47 * *$ & $0.39 * *$ \\
\hline Subjugation & $0.49 * *$ & $0.32 * *$ & $0.26 * *$ & $0.43 * *$ & $0.58 * *$ & $0.34 * *$ \\
\hline Self-sacrifice & $0.17 *$ & $0.19 *$ & 0.12 & 0.13 & 0.16 & 0 \\
\hline Emotional inhibition & $0.38 * *$ & $0.35 * *$ & $0.18 *$ & $0.30^{* *}$ & $0.38^{* *}$ & $0.18^{*}$ \\
\hline Unrelenting Standards /Hypercriticalness & $0.34 * *$ & $0.33 * *$ & $0.21 *$ & $0.33 * *$ & $0.23 * *$ & 0.12 \\
\hline Entitlement/Grandiosity & $0.33 * *$ & $0.27 * *$ & 0.13 & $0.22 * *$ & $0.37 * *$ & $0.28 * *$ \\
\hline Insufficient Self-Control/Self- discipline & $0.43 * *$ & $0.29 * *$ & 0.16 & $0.37 * *$ & $0.51 * *$ & $0.35^{* *}$ \\
\hline
\end{tabular}

Note. $\mathrm{COWC}=$ Contamination obsessions and Washing compulsions, $\mathrm{DRGRC}=$ dressing/grooming compulsion, $\mathrm{CHCK}=$ Checking compulsions, $\mathrm{OTAHSO}=$ Obsessional thoughts about harm to self $/$ others, OITHSO $=$ Obsessional impulses to harm self/others, ${ }^{* *}=\mathrm{P}<0.001,{ }^{*}=\mathrm{P}<0.05$.

Table 3. Abstract model of stepwise regression for prediction of active schemas in obsessive compulsive symptoms

\begin{tabular}{|c|c|c|c|c|c|c|c|c|}
\hline & & EMSs & & Beta & $\begin{array}{l}\text { R } \\
\text { Square }\end{array}$ & $\begin{array}{l}\text { Adjusted R } \\
\text { Square }\end{array}$ & $\mathbf{T}$ & $\begin{array}{l}P \\
\text { value }\end{array}$ \\
\hline \multirow{2}{*}{$\begin{array}{l}\text { general score of obsessive } \\
\text { compulsive symptoms }\end{array}$} & 1 & \multicolumn{2}{|l|}{ Defectiveness/Shame } & 0.54 & 0.29 & 0.29 & 7.55 & 0.000 \\
\hline & 2 & $\begin{array}{l}\text { Vulnerability to } \\
\text { Illness }\end{array}$ & Harm or & 0.34 & 0.38 & 0.37 & 4.23 & 0.000 \\
\hline \multirow{2}{*}{$\begin{array}{l}\text { contamination obsession and } \\
\text { washing compulsions }\end{array}$} & 1 & \multicolumn{2}{|l|}{ Defectiveness/Shame } & 0.44 & 0.20 & 0.19 & 5.81 & 0.000 \\
\hline & 2 & $\begin{array}{l}\text { Unrelenting } \\
\text { /Hypercriticalness }\end{array}$ & Standards & 0.19 & 0.23 & 0.22 & 2.45 & 0.015 \\
\hline \multirow[t]{2}{*}{$\begin{array}{l}\text { dressing/grooming } \\
\text { compulsion }\end{array}$} & 1 & \multicolumn{2}{|l|}{ Defectiveness/Shame } & 0.33 & 0.11 & 0.10 & 4.11 & 0.000 \\
\hline & 1 & Social Isolation/Alic & enation & 0.44 & 0.19 & 0.19 & 5.79 & 0.000 \\
\hline \multirow[t]{2}{*}{ checking compulsion } & 2 & $\begin{array}{l}\text { Vulnerability to } \\
\text { Illness }\end{array}$ & Harm or & 0.27 & 0.25 & 0.24 & 3.11 & 0.002 \\
\hline & 3 & $\begin{array}{l}\text { Unrelenting } \\
\text { /Hypercriticalness }\end{array}$ & Standards & 0.16 & 0.27 & 0.26 & 2.10 & 0.038 \\
\hline \multirow{3}{*}{$\begin{array}{l}\text { obsessional thoughts about } \\
\text { harm to self/others }\end{array}$} & 1 & $\begin{array}{l}\text { Vulnerability to } \\
\text { Illness }\end{array}$ & Harm or & 0.67 & 0.45 & 0.45 & 10.60 & 0.000 \\
\hline & 2 & Failure & & 0.26 & 0.51 & 0.50 & 4.06 & 0.000 \\
\hline & 3 & Subjugation & & 0.17 & 0.52 & 0.51 & 2.01 & 0.046 \\
\hline \multirow[b]{2}{*}{$\begin{array}{l}\text { obsessional impulses to harm } \\
\text { self/others }\end{array}$} & 1 & Defectiveness/Sham & & 0.49 & 0.24 & 0.24 & 6.62 & 0.000 \\
\hline & 2 & $\begin{array}{l}\text { Vulnerability to } \\
\text { Illness }\end{array}$ & Harm or & 0.24 & 0.28 & 0.27 & 2.80 & 0.006 \\
\hline
\end{tabular}


Table 3 shows that Defectiveness/Shame and Vulnerability to Harm or Illness early maladaptive schemas had the highest correlation with the general score of obsessive compulsive symptoms (Table 2). They enter the regression equation and two above-mentioned schemas explain the 0.38 percent $\left(\mathrm{r}^{2}=0.38\right)$ of the variance of obsessive compulsive symptoms' general score.

Early maladaptive schemas of Defectiveness/Shame and Unrelenting Standards/Hypercriticalness which have the highest correlation with contamination obsession and compulsive washing (Table 2), entered the regression equation and explain 0.23 percent $\left(\mathrm{r}^{2}=0.23\right)$ of their variances. Moreover, Defectiveness/Shame schema predicts 11 percent $\left(\mathrm{r}^{2}=0.11\right)$ of dressing/grooming compulsion variance.

As it can be drawn from Table 2, in the first step Social Isolation/Alienation schema, in the second step Vulnerability to Harm and Illness schema, and in the third step Unrelenting Standards/Hypercriticalness schema have entered the equation and explain 27 percent $\left(\mathrm{r}^{2}=0.27\right)$ of checking compulsion variance.

Vulnerability to Harm and Illness, Failure, and Subjugation schemas have entered the regression equation; and other schemas have been deleted. From the equation these three schemas explain 52 percent $(\mathrm{r} 2=0.52)$ of obsessional thoughts about harm to self or others variance.

According to Table 3, early maladaptive schemas of Defectiveness/Shame and Vulnerability to Harm and Illness have the highest correlation with obsessional impulses to harm oneself or others (Table 2). 0.28 percent $(\mathrm{r} 2=0.28)$ of obsessional impulses to harm oneself or others is explained by these two schemas.

\section{Discussion}

The distribution pattern of EMSs in three groups reveals that schemas are equally distributed in them (Figure 1). This fact is in line with Young's theory which asserts schemas are dimensional and are only different from each other in respect of severity and activity domain in the mind (Young et al., 2003), and This is an affirmation of the dimensional approach in DSM5 (DSM-5 2013).

The results of comparing anxiety disorder group and control groups comes as following: all early maladaptive schemas, except Self-Sacrifice, Unrelenting Standards/Hyperactiveness, Entitlement/Grandiosity, are more active in anxiety disorders group in comparison to control group. This fact is in line with some researches and against some others; for instance in previous researches regarding anxiety disorders, there have been tracks of Vulnerability to Harm and Illness schema (Hedley et al., 2001; Hinrichsen et al., 2004; Kwak \& Lee, 2015) and self-sacrifice (Kwak \& Lee, 2015) in panic disorder; of Abandonment/Instability, Emotional Inhibition (Hinrichsen et al., 2004) and Defectiveness/Shame, Mistrust/Abuse, Emotional Deprivation, and Unrelenting Standards/Hypercriticalness (Pinto-Gouveia et al., 2006) schemas in social phobia; and of Emotional Inhibition, Unrelenting Standards/Hypercriticalness, Mistrust/Abuse, Entitlement/Grandiosity, Insufficient Self-control/Self-discipline (Edworthy et al., 2008), Defectiveness/Shame, Dependence/Incompetence, Enmeshment/Undeveloped Self and Failure (Price, 2007), Vulnerability to Harm and Illness (Cockram et al., 2010) in post-traumatic stress disorder.

Findings of comparison between OCD and control group revealed that all early maladaptive schemas are significantly more active in OCD group. Noei et al's research in 2010 (Noie et al., 2010) which had compared the role of EMSs and their parental roots in patients suffering from OCD and a non-clinical group, proved the significant difference of EMSs in OCD group. Findings of the research are in line with those of the present study. On the other hand, Atalay et al. (2008) in their comparison between control group and with OCD group found out that the latter received significantly higher score than control group especially in Social Isolation/Alienation, Vulnerability to Harm and Illness, and Negativity/Pessimism schemas (Atalay et al., 2008). In another study Patients with OCD had significantly higher scores for schema related to defectiveness/shame (Kim et al., 2014; Lee, Won, \& Lee, 2010) social isolation/alienation, and failure (Kim et al., 2014) than did normal controls.

According to cognitive pathology model, all early maladaptive schemas would be possible to be activated in the condition of emotional disorder (Young et al., 2003). However, nonspecific activation of all early maladaptive schemas is not of a great help in predicting the type of emotional disorder. Therefore a comparison was held among three groups and the findings revealed that there is a significant difference among the three groups except in Self-Sacrifice, Unrelenting Standards/Hypercriticalness, and Entitlement/Grandiosity schemas. The results of post hoc test showed that two clinical groups are significantly different, OCD group having the higher score, in Self-Sacrifice, Unrelenting Standards/Hypercriticalness, and Entitlement/Grandiosity schemas. These three schemas are specific to OCD. Lochner et al. in 2005 made a comparison between patients suffering from OCD and trichotillomania which revealed the Defectiveness/Shame, Mistrust/Abuse, Social Isolation/Alienation, and Emotional Inhibition schemas are more active in OCD group than anxiety disorders group (Lochner et al., 2005). 
Since there was no control group in this research, one cannot conclude that these schemas are specific to OCD. In spite of this limitation, Defectiveness/Shame and Mistrust/Abuse schemas are reported as specific to OCD in both Lochner's and our research. Also, the score of defectiveness/shame and vulnerability to Harm and Illness schemas were different between patients with panic disorder and OCD (Kwak \& Lee, 2015).

According to comorbidity of OCD with anxiety disorders, those diagnosed mainly with OCD could be suffering also from other anxiety disorders (Sadock, 2007). Therefore, similarity of schemas between the two groups might be the result of their comorbidity; however, since the three schemas of Self-Sacrifice, Unrelenting Standards/Hypercriticalness, and Entitlement/Grandiosity are specific to OCD, pathology of two disorders seems to be different and therefore need different treatments. And this is in line with DSM-5 changes in separation of diagnostic levels of OCD and anxiety disorders.

In the domain of predicting obsessive compulsive symptoms by EMSs, results of stepwise regression showed that Defectiveness/Shame and Vulnerability to harm and Illness schemas predict 38 percent of variance of obsessive compulsive symptoms, Defectiveness/Shame schema having the greater share (29 percent). Since this schema is one of the three specific schemas of OCD (Defectiveness/Shame, Emotional Deprivation, and Mistrust/Abuse), it is expected to be partially anticipant of symptoms of the disorder. It seems that due to the high correlation of Defectiveness/Shame schema with Emotional Deprivation and Mistrust/Abuse schemas, these two schemas did not enter the regression equation and Vulnerability to Harm and Illness schema is the second anticipant factor of obsessive compulsive symptoms. Study of Kim et al. in 2014 showed two schemas Vulnerability to Harm or Illness and Enmeshment/Undeveloped Self, can predict 33 percent of the variance in sexual/religious dimension (Kim et al., 2014).

In addition to generally predicting obsessive compulsive symptoms, Defectiveness/Shame schema predicts three other subtypes which are namely contamination obsession and compulsive washing (20 percent), dressing/grooming compulsion (11 percent), and obsessional impulses to harm oneself or others (24 percent). These results are in close agreement with the study on Shame in the obsessive compulsive related disorders, which found that general shame and shame about having a mental illness are relevant to obsessive compulsive related disorders (Weingarden \& Renshaw, 2015). Clark (2004) believes that ambivalence self- assessment is one of the vulnerability factors to obsessions and compulsions, in fact these confilctual, vague and ambivalence feelings towards oneself along with feeling defect make people potential of misunderstanding the threat(Clark, 2004).

The findings of the present study show that Vulnerability to Harm and Illness schema explains 45 percent of variance of obsessional thoughts about harm to self or others and has the role of second anticipant in obsessional impulses to harm self or others and checking compulsions. Vulnerability to Harm or Illness is defined as extreme fear caused by the thought that the disaster is close and is likely to happen any minute and it cannot be prevented.

Due to the fact that EMSs specific to OCD are all related to disconnection and rejection domain; and the patients whose schemas are located in this domain are not able to make safe and satisfying attachments to others, it is suggested therapeutic relationship be taken into consideration as a central component in treatment of this group of patients. Since OCD is a heterogeneous disorder and contains various subtypes, it is suggested that clinical intervention happens prioritizing the symptom anticipant schema. According to the findings of this research, Defectiveness/Shame schema has a greater role in predicting symptoms of OCD; therefore, it is expected to take it more serious in OCD clinical intervention.

One of the limitations of the present research is the fact that assessment of EMSs just happened through self-report which could have affected the validity of the results. Reports about patients can be affected by the fact that they are in various stages of treatment and some of them were taking different medications.

\section{Suggestions}

In order to certify about the fact that early maladaptive schemas, active in each patient, are congruous with the results of Young schema questionnaire, it is better to do a qualitative research on a number of patients. Moreover, a specific treatment plan can be prepared by considering active schemas in OCD group.

\section{Conflict of Interest}

The authors declare that there is no conflict of interests regarding the publication of this paper.

\section{References}

Abela, J. R., Auerbach, R. P., Sarin, S., \& Lakdawalla, Z. (2009). Core beliefs and history of major depressive episodes in currently non-depressed university students. Cognitive Therapy and Research, 33(1), 50-58. http://dx.doi.org/10.1007/s10608-008-9185-y 
Ahi, G. (2006). Young Schema Questionnaire-Short Normalization. University of Allameh Tabatabai, Tehran.

Anderson, K., Rieger, E., \& Caterson, I. (2006). A comparison of maladaptive schemata in treatment-seeking obese adults and normal-weight control subjects. Journal of Psychosomatic Research, 60(3), 245-252. http://dx.doi.org/10.1016/j.jpsychores.2005.08.002

Atalay, H., Atalay, F., Karahan, D., \& Çaliskan, M. (2008). Early maladaptive schemas activated in patients with obsessive compulsive disorder: A cross-sectional study. International journal of psychiatry in clinical practice, 12(4), 268-279. http://dx.doi.org/10.1080/13651500802095004

Ball, S. A., \& Cecero, J. J. (2001). Addicted patients with personality disorders: Traits, schemas, and presenting problems. Journal of Personality Disorders, 15(1), 72-83. http://dx.doi.org/10.1521/pedi.15.1.72.18642

Beck, A. T., Freeman, A., \& Davis, D. (2004). Cognitive therapy of personality disorders. NY: Guilford Publications, Inc.

Brewin, C. R., Andrews, B., \& Valentine, J. D. (2000). Meta-analysis of risk factors for posttraumatic stress disorder in trauma-exposed adults. Journal of Consulting and Clinical Psychology, 68(5), 748. http://dx.doi.org/10.1037/0022-006X.68.5.748

Brotchie, J., Meyer, C., Copello, A., Kidney, R., \& Waller, G. (2004). Cognitive representations in alcohol and opiate abuse: The role of core beliefs. British Journal of Clinical Psychology, 43(3), 337-342. http://dx.doi.org/10.1348/0144665031752916

Burns, G. L., Formea, G. M., Keortge, S., \& Sternberger, L. G. (1995). The utilization of nonpatient samples in the study of obsessive compulsive disorder. Behaviour Research and Therapy, 33(2), 133-144. http://dx.doi.org/10.1016/0005-7967(94)00039-M

Calvete, E., Estévez, A., López de Arroyabe, E., \& Ruiz, P. (2005). The Schema Questionnaire-Short Form. European Journal of Psychological Assessment, 21(2), 90-99. http://dx.doi.org/10.1027/1015-5759.21.2.90

Carr, S. N., \& Francis, A. J. (2010). Do early maladaptive schemas mediate the relationship between childhood experiences and avoidant personality disorder features? A preliminary investigation in a non-clinical sample. Cognitive Therapy and Research, 34(4), 343-358. http://dx.doi.org/10.1007/s10608-009-9250-1

Clark, D. A. (2004). Cognitive-behavioral therapy for OCD. Guilford Press.

Cockram, D. M., Drummond, P. D., \& Lee, C. W. (2010). Role and treatment of early maladaptive schemas in Vietnam veterans with PTSD. Clinical Psychology \& Psychotherapy, 17(3), 165-182. http://dx.doi. org/10.1002/cpp.690

Delattre, V., Servant, D., Rusinek, S., Lorette, C., Parquet, P.-J., Goudemand, M., \& Hautekeete, M. (2004). Les schémas précoces dysfonctionnels: Étude chez des patients' adultes souffrant d'un trouble anxieux. L'Encéphale, 30(3), 255-258. http://dx.doi.org/10.1016/S0013-7006(04)95437-1

DSM-5, A. P. A. (2013). Diagnostic and statistical manual of mental disorders. Arlington: American Psychiatric Publishing.

Dutra, L., Callahan, K., Forman, E., Mendelsohn, M., \& Herman, J. (2008). Core schemas and suicidality in a chronically traumatized population. The Journal of Nervous and Mental Disease, 196(1), 71-74. http://dx.doi.org/10.1097/NMD.0b013e31815fa4c1

Edworthy, Z., Chasey, R., \& Williams, H. (2008). The role of schema and appraisals in the development of post-traumatic stress symptoms following birth. Journal of Reproductive and Infant Psychology, 26(2), 123-138. http://dx.doi.org/10.1080/02646830801918422

Esfahani, S. R. M. Y., Kamkari, K., Zahiredin, A., \& Janbozorgi, M. (2012). Reliability and Validity of the Persian version of the Yale-Brown Obsessive-Compulsive scale (Y-BOCS). Iranian Journal of Psychiatry and Clinical Psychology, 17(4), 297-303.

First, M. B., Spitzer, R. L., Gibbon, M., \& Williams, J. B. (1997). User's guide for the structured clinical interview for DSM-IV axis I disorders SCID-I: Clinician version: American Psychiatric Pub.

Goldberg, D. P., \& Hillier, V. F. (1979). A scaled version of the General Health Questionnaire. Psychological medicine, 9(1), 139-145. http://dx.doi.org/10.1017/S0033291700021644

Goodman, W. K., Price, L. H., Rasmussen, S. A., Mazure, C., Fleischmann, R. L., Hill, C. L., ... Charney, D. S. (1989). The Yale-Brown obsessive compulsive scale: I. Development, use, and reliability. Archives of General Psychiatry, 46(11), 1006-1011. http://dx.doi.org/10.1001/archpsyc.1989.01810110048007 
Hadibahrami, E., \& Bahramizadeh, H. (2011). Early Maladaptive Schemas and Agreeableness in Personality Five Factor Model. Procedia-Social and Behavioral Sciences, 30, 547-551. http://dx.doi.org/10.1016/j. sbspro.2011.10.107

Harris, A. E., \& Curtin, L. (2002). Parental perceptions, early maladaptive schemas, and depressive symptoms in young adults. Cognitive Therapy and Research, 26(3), 405-416. http://dx.doi.org/10.1023/A:1016 085112981

Hawke, L. D., \& Provencher, M. D. (2011). Schema theory and schema therapy in mood and anxiety disorders: A review. Journal of Cognitive Psychotherapy, 25(4), 257-276. http://dx.doi.org/10.1891/0889-8391. 25.4.257

Hedley, L. M., Hoffart, A., \& Sexton, H. (2001). Early maladaptive schemas in patients with panic disorder with agoraphobia. Journal of Cognitive Psychotherapy, 15(2), 131-142.

Hinrichsen, H., Waller, G., \& Emanuelli, F. (2004). Social Anxiety and Agoraphobia in the Eating Disorders: Associations with Core Beliefs. The Journal of Nervous and Mental Disease, 192(11), 784-787. http://dx.doi.org/10.1097/01.nmd.0000144698.69316.02

Jovev, M., \& Jackson, H. J. (2004). Early maladaptive schemas in personality disordered individuals. Journal of Personality Disorders, 18(5), 467-478. http://dx.doi.org/10.1521/pedi.18.5.467.51325

Kim, J. E., Lee, S. W., \& Lee, S. J. (2014). Relationship between early maladaptive schemas and symptom dimensions in patients with obsessive-compulsive disorder. Psychiatry research, 215(1), 134-140. http://dx.doi.org/10.1016/j.psychres.2013.07.036

Kwak, K.-H., \& Lee, S. J. (2015). A comparative study of early maladaptive schemas in obsessive-compulsive disorder and panic disorder. Psychiatry research, 230(3), 757-762. http://dx.doi.org/10.1016/j.psychres. 2015.11.015

Lee, S., Won, S., \& Lee, S. (2010). Characteristic maladaptive schemas in patients with obsessive compulsive disorder. Cognitive Behavior Therapy in Korea, 10, 75-91.

Leung, N., Waller, G., \& Thomas, G. (1999). Core beliefs in anorexic and bulimic women. The Journal of nervous and mental disease, 187(12), 736-741. http://dx.doi.org/10.1097/00005053-199912000-00005

Lochner, C., Seedat, S., Du Toit, P. L., Nel, D. G., Niehaus, D. J., Sandler, R., \& Stein, D. J. (2005). Obsessive-compulsive disorder and trichotillomania: A phenomenological comparison. BMC psychiatry, 5(1), 2. http://dx.doi.org/10.1186/1471-244X-5-2

Lumley, M. N., \& Harkness, K. L. (2007). Specificity in the relations among childhood adversity, early maladaptive schemas, and symptom profiles in adolescent depression. Cognitive Therapy and Research, 31(5), 639-657. http://dx.doi.org/10.1007/s10608-006-9100-3

Manesh, E. H., Baf, H. R. A. M. S., Abadi, B. A. G. H., \& Mahram, B. (2010). Early maladaptive schemas and schema domains in rapists. Iranian Journal of Psychiatry and Clinical Psychology, 16(2), 145-153.

Mohammadi, M., Davidiyan, H., Noorbala, A., Afzali, M., Hussein, \& Naqvi, H. (2005). The epidemiology psychiatric disorders in the Kerman. Hakim Research Journal, 6(1), 55-65.

Mohammadi, M., Rahgozar, M., Mesgarpor, B., Farrokh, K., Gharedaghi, K., \& Norolahi, S. (2004). The epidemiology of psychiatric disorders in the East Azerbaijan in 1380. Journal of Tabriz University of Medical Sciences, 38(64), 67-73.

Mohammadkhani, P., Jahanitabesh, O., \& Tamanaii far, S. (2006). Structured Clinical Interview for DSM-IV Disorders. Tehran: Faradid.

Moloodi, R., Dezhkam, M., Mootabi, F., \& Omidvar, N. (2010). Comparison of early maladaptive schema in obese binge eaters and obese non-binge eaters. Journal of Behavioral Sciences, 4(2), 109-114.

Nazifi, M., Mokarami, H., Akbaritabar, A., Faraji Kujerdi, M., Tabrizi, R., \& Rahi, A. (2014). Reliability, Validity and Factor Structure of the Persian Translation of General Health Questionnire (GHQ-28) in Hospitals of Kerman University of Medical Sciences. Journal of Fasa University of Medical Sciences, 3(4), 336-342.

Noie, Z., Farid, A. A., Fata, L., \& Ashoori, A. (2010). Comparison of early maladaptive schemas and their parental origins in OCD patients and non-clinical individuals. Advances in Cognitive Science, 12(1), 59-69.

Nordahl, H. M., Holthe, H., \& Haugum, J. A. (2005). Early maladaptive schemas in patients with or without 
personality disorders: Does schema modification predict symptomatic relief? Clinical Psychology \& Psychotherapy, 12(2), 142-149. http://dx.doi.org/10.1002/cpp.430

Petrocelli, J. V., Glaser, B. A., Calhoun, G. B., \& Campbell, L. F. (2001). Early maladaptive schemas of personality disorder subtypes. Journal of Personality Disorders, 15(6), 546-559. http://dx.doi.org/10.1521/ pedi.15.6.546.19189

Pinto-Gouveia, J., Castilho, P., Galhardo, A., \& Cunha, M. (2006). Early maladaptive schemas and social phobia. Cognitive Therapy and Research, 30(5), 571-584. http://dx.doi.org/10.1007/s10608-006-9027-8

Price, J. P. (2007). Cognitive schemas, defence mechanisms and post-traumatic stress symptomatology. Psychology and Psychotherapy: Theory, Research and Practice, 80(3), 343-353. http://dx.doi.org/10. 1348/147608306X144178

Reeves, M., \& Taylor, J. (2007). Specific relationships between core beliefs and personality disorder symptoms in a non-clinical sample. Clinical Psychology \& Psychotherapy, 14(2), 96-104. http://dx.doi. org/10.1002/cpp.519

Riso, L. P., \& Newman, C. F. (2003). Cognitive therapy for chronic depression. Journal of Clinical Psychology, 59(8), 817-831. http://dx.doi.org/10.1002/jclp.10175

Riso, L. P., du Toit, P. L., Stein, D. J., \& Young, J. E. (2007). Cognitive schemas and core beliefs in psychological problems: A scientist-practitioner guide: American Psychological Association. http://dx.doi.org/10.1037/11561-000

Sadock, B. J. S. V. (2007). Kaplan \& Sadock's synopsis of psychiatry: Behavioral sciences/clinical psychiatry.

Schmidt, N. B., Joiner Jr, T. E., Young, J. E., \& Telch, M. J. (1995). The schema questionnaire: Investigation of psychometric properties and the hierarchical structure of a measure of maladaptive schemas. Cognitive Therapy and Research, 19(3), 295-321. http://dx.doi.org/10.1007/BF02230402

Shams, G., Kaviani, H., Esmaili, T. Y., Ebrahimkhani, N., \& Amin, M. A. (2010). A study of Validity and Reliability of the Persian Version of the Padua Inventory-Washington State University Revision (PI-WSUR) in a Sample of Healthy Iranian Students.

Sines, J., Waller, G., Meyer, C., \& Wigley, L. (2008). Core beliefs and narcissistic characteristics among eating-disordered and non-clinical women. Psychology and Psychotherapy: Theory, Research and Practice, 81(2), 121-129. http://dx.doi.org/10.1348/147608307X267496

Specht, M. W., Chapman, A., \& Cellucci, T. (2009). Schemas and borderline personality disorder symptoms in incarcerated women. Journal of Behavior Therapy and Experimental Psychiatry, 40(2), 256-264. http://dx.doi.org/10.1016/j.jbtep.2008.12.005

Taylor SIRPS, S. A., Rachman, S., \& Richter, M. A. (Eds.). (1998). Obsessive-compulsive disorder: Theory, research and treatment. New York: GuildfordThimm.

Van Vlierberghe, L., \& Braet, C. (2007). Dysfunctional schemas and psychopathology in referred obese adolescents. Clinical Psychology \& Psychotherapy, 14(5), 342-351. http://dx.doi.org/10.1002/cpp.546

Voderholzer, U., Schwartz, C., Thiel, N., Kuelz, A. K., Hartmann, A., Scheidt, C. E., ... Zeeck, A. (2014). A comparison of schemas, schema modes and childhood traumas in obsessive-compulsive disorder, chronic pain disorder and eating disorders. Psychopathology, 47(1), 24-31. http://dx.doi.org/10.1159/000348484

Waller, G., Meyer, C., \& Ohanian, V. (2001). Psychometric properties of the long and short versions of the Young Schema Questionnaire: Core beliefs among bulimic and comparison women. Cognitive Therapy and Research, 25(2), 137-147. http://dx.doi.org/10.1023/A:1026487018110

Weingarden, H., \& Renshaw, K. D. (2015). Shame in the obsessive compulsive related disorders: A conceptual review. Journal of Affective Disorders, 171, 74-84. http://dx.doi.org/10.1016/j.jad.2014.09.010

Young, J. E. (1994). Cognitive therapy for personality disorders: A schema-focused approach (rev: Professional Resource Press/Professional Resource Exchange.

Young, J. E. (1999). Young schema questionnaire. In J. E. Young (Eds.), Cognitive therapy for personality disorders: A schema-focused approach. Sarasota.

Young, J. E., Klosko, J. S., \& Weishaar, M. E. (2003). Schema therapy: A practitioner's guide. Guilford Press. 


\section{Copyrights}

Copyright for this article is retained by the author(s), with first publication rights granted to the journal.

This is an open-access article distributed under the terms and conditions of the Creative Commons Attribution license (http://creativecommons.org/licenses/by/3.0/). 